\title{
O PAPEL INSTITUCIONAL DO PODER JUDICIÁRIO NAS QUATRO DIMENSÕES DO SISTEMA DE JUSTIÇA DE TRANSIÇÃO
}

\author{
Eneá de Stutz e Almeida ${ }^{1}$ \\ Marcelo Pires Torreão ${ }^{2}$
}

\section{RESUMO:}

Este artigo objetiva analisar como as dimensões da Justiça de Transição podem ser realizadas pelo Poder Judiciário. A retrospectiva histórica mostra uma redução de autonomia do Poder Judiciário durante a ditadura, mas também uma certa conivência desse poder com o regime de exceção. O estudo mostra que as decisões proferidas pelo Judiciário têm capacidade de interferir diretamente no processo de justiça de transição brasileira nos quatro pilares conceituais. Conclui-se pela necessidade de mudança do pensamento institucional, a fim de que o Poder Judiciário, consciente e comprometido com o processo transicional, possa reduzir conflitos e construir uma democracia socialmente legitimada.

Palavras-chave: Justiça de Transição; Dimensões; Judiciário; Conflitos; Sociedade; Ditadura; Instituições

\section{THE INSTITUTIONAL ROLE OF THE JUDICIARY IN THE FOUR DIMENSIONS OF THE TRANSITIONAL JUSTICE SYSTEM}

\begin{abstract}
:
This article aims to analyses how the Judiciary can perform the dimensions of Transitional Justice. A historical research shows a reduction of the independency of the Judiciary during the dictatorship, but also some permission for the exception regime. The scrutiny shows that the Judiciary decisions have capacity of interfering directly in the Brazilian process of transitional justice in its four conceptual grounds. Hence, there is a need of change thereof the institutional thinking, in order to create an awareness and a commitment from the Judiciary in the transitional process to reduce conflicts and build a socially legitimized democracy.
\end{abstract}

Keywords: Transitional Justice; Dimensions; Judiciary; Conflicts; Society; Dictatorship; Institutions

\section{INTRODUÇÃO}

O estudo apresentado pretende responder à seguinte indagação: qual tem sido o papel do Poder Judiciário diante das quatro dimensões da Justiça de Transição no Brasil, a saber, a reparação das vítimas, o processamento dos violadores de direitos humanos, a reforma das instituições e a memória/verdade? Para tanto, foram coletados julgados recentes e utilizou-se a metodologia bibliográfica-documental.

\footnotetext{
${ }^{1}$ Graduada e Mestre em Direito pela Universidade do Estado do Rio de Janeiro e Doutora em Direito pela Universidade Federal de Santa Catarina. É professora adjunta da Universidade de Brasília - UnB.

${ }^{2}$ Advogado e professor. Especializado em recursos nos tribunais superiores, direitos humanos, anistia política, direito administrativo e agências reguladoras.
} 
A hipótese que se quer defender é que o Judiciário tem sido chamado a se pronunciar em todas as dimensões desse tema tão difícil e nebuloso no Brasil. Entre as causas dos conflitos existentes na sociedade brasileira atual, uma parte significativa decorre dos déficits transicionais e, nessa linha de raciocínio, os três Poderes da República possuem protagonismo importante para que se alcance um efetivo Estado Democrático de Direito.

Inicialmente, se apreciará a conduta do Judiciário durante o período autoritário, num brevíssimo relato. Na sequência, uma observação mais apurada de cada uma das dimensões apontadas e a relação do Judiciário com cada uma delas. Ao final, à guisa de conclusão, uma reflexão sobre a necessidade de o Judiciário, ele próprio, submeter-se a uma reforma institucional e assim cumprir com sua atuação primordial, qual seja, a prestação da Justiça num país democrático.

\section{O Poder Judiciário na Ditadura Militar}

Desde a Constituição de 1824, estava expressa a independência do chamado Poder Judicial, além da harmonia dos demais poderes políticos do Império $^{3}$. Essas características foram repetidas em todas as cartas constitucionais seguintes.

Na Constituição Federal de 1946, o Poder Judiciário passou a ser composto pelo Supremo Tribunal Federal, Tribunal Federal de Recursos, além dos juízes e tribunais de competência especializada nas áreas militar, eleitoral e trabalhista ${ }^{4}$. Não existia a figura dos juízos federais de primeira instância ${ }^{5}$. A previsão constitucional da justiça estadual limitava-se a um quadro de princípios que deveriam ser observados pelos Estados ao elaborarem as normas das respectivas organizações judiciárias ${ }^{6}$. O diploma constitucional de 1946 foi o primeiro a expressar o princípio constitucional da inafastabilidade do Poder Judiciário no capítulo das garantias individuais dos cidadãos ${ }^{7}$.

A partir do Golpe Militar de 1964, esse princípio constitucional que garantia o amplo e livre acesso ao Poder Judiciário passou a ser mitigado. As primeiras alterações ocorreram já

\footnotetext{
${ }^{3}$ Constituição de 1824. Artigos 10 e 151.

${ }^{4}$ Constituição Federal de 1946. Artigo 94.

${ }^{5}$ A Justiça Federal de primeira instância havia sido extinta pelo artigo 185 da Constituição Federal de 1937.

${ }^{6}$ Constituição Federal de 1946. Artigo 124.

${ }^{7}$ Constituição Federal de 1946. Artigo 141.
} 
na edição do Ato Institucional $\mathrm{n}^{\mathrm{o}}$ 1, quando foram suspensas as garantias legais $\mathrm{e}$ constitucionais de estabilidade e vitaliciedade, de modo a permitir a demissão, dispensa ou aposentadoria de qualquer servidor público ${ }^{8}$. Os fatos ou fundamentos que tivessem justificado esse tipo de penalidade não poderiam ser revisados pelo Poder Judiciário, que estava limitado a analisar apenas as formalidades do ato de demissão ${ }^{9}$. Os atos de cassação de mandatos legislativos e de suspensão dos direitos políticos também foram expressamente excluídos do controle judicial ${ }^{10}$.

O Ato Institucional $n^{\circ} 2$ foi o responsável por recriar a Justiça Federal de primeira instância, integrada por juízes nomeados pelo Presidente da República ${ }^{11}$. Esse ato ampliou o número de Ministros do Supremo Tribunal Federal de onze para dezesseis e criou o Superior Tribunal Militar, composto por quinze ministros nomeados pelo Chefe de Governo ${ }^{12}$. Após a edição do Ato Institucional nº 2, quaisquer práticas governamentais fundamentadas em ato de natureza institucional passaram a ser excluídas da revisão judicial ${ }^{13}$.

No Ato Institucional $\mathrm{n}^{\mathrm{o}}$ 3, mais uma vez, foi afastada a competência do Poder Judiciário para apreciar as medidas institucionais do governo autoritário ${ }^{14}$. O Ato Institucional $\mathrm{n}^{\mathrm{o}} 5$ eliminou a possibilidade de atuação judicial para analisar as medidas de segurança adotadas pelo Ministro da Justiça ${ }^{15}$. Esse ato institucional proibiu o controle judicial não apenas dos atos fundamentados em normas institucionais, mas também de todos os efeitos que delas decorressem ${ }^{16}$. Essa ampliada vedação foi reproduzida nos Atos Institucionais de números 6 e 7, que contaram com idêntica redação ${ }^{17}$.

Com a edição do Ato Institucional n 6, a composição do Supremo Tribunal Federal foi reduzida de dezesseis para onze ministros e foi mantida a competência exclusiva da Justiça Militar para o julgamento de crimes contra a segurança nacional, sem a possibilidade de

\footnotetext{
${ }^{8}$ Ato Institucional $\mathrm{n}^{\circ} 1$. Artigo $7^{\circ}$.

${ }^{9}$ Ato Institucional $\mathrm{n}^{\circ} 1$. Artigo $7^{\circ}, \S 4^{\circ}$.

${ }^{10}$ Ato Institucional ${ }^{\circ} 1$. Artigo 10.

${ }^{11}$ Art. $6^{\circ}$ do Ato Institucional no 2, que modificou o artigo 105 da Constituição de 1934.

${ }^{12}$ Art. $7^{\circ}$ do Ato Institucional $n^{\circ} 2$ e Artigo $6^{\circ}$ do Ato Institucional no 2, que alterou o artigo 98 da Constituição Federal.

${ }^{13}$ Ato Institucional $\mathrm{n}^{\circ} 2$. Art. 19.

${ }^{14}$ Artigo $6^{\circ}$ do Ato Institucional ${ }^{\circ} 3$.

${ }^{15}$ Ato Institucional $\mathrm{n}^{\circ} 5$. Artigo $5^{\circ}$.

${ }^{16}$ Ato Institucional ${ }^{\circ} 5$. Artigo 11.

${ }^{17}$ Artigo $4^{\circ}$ do Ato Institucional $\mathrm{n}^{\circ}$ 6; artigo $9^{\circ}$ do Ato Institucional $\mathrm{n}^{\circ} 7$.
} 
interposição de recursos para o Supremo Tribunal Federal ${ }^{18}$. O Ato Institucional $\mathrm{n}^{\mathrm{o}} 11$ extinguiu a Justiça de Paz eletiva ${ }^{19}$. Nos atos institucionais de números 12 a 17, foi repetida a impossibilidade de análise judicial de qualquer efeito decorrente da aplicação de normas institucionais ${ }^{20}$.

Portanto, entre os anos de 1964 a 1969, as sucessivas edições de atos institucionais interferiram diretamente na atividade judicial. Essas alterações normativas ocorreram em duas linhas, uma com a finalidade de reduzir o controle judicial comum e outra com o objetivo de ampliar a atuação da justiça federal de primeira instância e da justiça militar especializada naquelas questões de interesse do governo ditatorial.

Por um lado, a exclusão da revisão judicial em matérias de interesse do governo militar revelava a redução do campo de atuação e da independência dos órgãos do Poder Judiciário existentes à época. A mesma finalidade estava estampada na diminuição do número de ministros do Supremo Tribunal Federal, ocasionada após a saída de cinco magistrados daquela corte por motivações políticas ${ }^{21}$.

Por outro, houve um alargamento da estrutura organizacional judiciária que permitiu a inclusão de magistrados de plena confiança do governo ditatorial na justiça federal de primeira instância e no Superior Tribunal Militar. Além do reforço estrutural, foram ampliadas as competências da Justiça Militar, braço direito do Poder Executivo para o julgamento de todas as questões relacionadas à suposta segurança nacional.

Sem dúvida, as alterações impostas por atos institucionais exerceram grande pressão sobre o Poder Judiciário. Em um cenário ilustrado por repressões, arbitrariedades e violências, o Judiciário mostrava-se cada vez menos capaz de exercer as atividades de julgamento com liberdade e plenitude.

\footnotetext{
${ }^{18}$ Ato Institucional no 6, que alterou o artigo 112, § $1^{\circ}$, da Constituição de 1967.

19 Ato Institucional $\mathrm{n}^{\circ} 11$. Art. $4^{\circ}$.

${ }^{20}$ Artigo $5^{\circ}$ do Ato Institucional $n^{\circ} 12$; artigo $2^{\circ}$ do Ato Institucional $n^{\circ} 13$; artigo $3^{\circ}$ do Ato Institucional $\mathrm{n}^{\circ} 14$; artigo $4^{\circ}$ do Ato Institucional $n^{\circ} 15$; artigo $8^{\circ}$ do Ato Institucional n ${ }^{\circ} 16$; $\operatorname{artigo} 4^{\circ}$ do Ato Institucional ${ }^{\circ} 17$.

${ }^{21}$ No dia 16 de janeiro 1969, os Ministros Hermes Lima, Victor Nunes Leal e Evandro Lins e Silva, considerados de orientação esquerdista pelos militares, foram compulsoriamente aposentados com fundamento no Ato Institucional $\mathrm{n}^{\circ}$ 5. Em protesto a essas aposentadorias, os Ministros Gonçalves de Oliveira e Antônio Carlos Lafayette de Andrada também deixaram a corte.
} 
Todavia, mesmo diante dos temores do totalitarismo e da redução de competências, o Poder Judiciário continuou a ser o principal detentor da função judicante, por meio da aplicação de normas e da solução de litígios nos casos em concreto. Justamente no exercício da função jurisdicional, esse poder apresentou-se, em várias oportunidades, de forma conivente com o regime de exceção e silenciou quanto a graves violações a direitos humanos ocorridas durante o governo militar.

Uma das linhas de investigação da Comissão Nacional da Verdade dedicou-se a estudar a atuação do Poder Judiciário na ditadura ${ }^{22}$. Nesse exame, a comissão observou que, mesmo antes mesmo da edição dos primeiros atos institucionais, já existiam decisões do Supremo Tribunal Federal, nas quais não se conhecia de habeas corpus impetrados por pacientes civis acusados de crimes políticos, com base no conveniente entendimento de que a autoridade coatora era militar ${ }^{23}$. Além disso, o Supremo Tribunal Federal também oscilou quanto à possibilidade de conhecer da matéria em casos de excesso de prazo para prisão ${ }^{24}$.

Em outro exemplo, o Supremo Tribunal Federal analisou a forma de nomeação de juízes federais. Embora o Ato Institucional no 2 e a Lei 5.010/66 estabelecessem a nomeação de juízes por ato do Presidente da República, a Constituição Federal de 1967 passou a exigir a aprovação em concursos de provas e títulos para investidura nesses cargos. Nos anos de 1967 e 1968, o Supremo Tribunal Federal decidiu pela prevalência das nomeações de juízes por ato

\footnotetext{
22 “[...] essa política de Estado teve repercussão nos outros poderes - notadamente, no Judiciário -, que, por força de suas atribuições constitucionais, tiveram de lidar com as graves violações de direitos humanos, examinando, por meio de procedimentos próprios, situações dessa natureza. Para a CNV, é relevante a constatação de que, em que pesem o caráter antidemocrático do regime, com a consequente hipertrofia do Executivo e a censura que se estabeleceu sobre os meios de comunicação social, no âmbito do Poder Judiciário se deu, à época em que ocorriam, a apreciação dessas condutas ilícitas por parte de agentes públicos" (BRASIL, 2014, p. 934).

${ }^{23}$ Vale observar o seguinte trecho da Comissão Nacional da Verdade: "Em suma, eis o quadro do STF às vésperas da edição do AI-2: uma corte que se mostrou hesitante no que diz respeito ao critério a ser utilizado na definição de competência para julgar crimes políticos cometidos por civis, mas preocupou-se em controlar algumas das arbitrariedades e excessos praticados no âmbito do inquérito policial-militar" (Ibidem, p. 942).

${ }^{24}$ Constam registros de pessoas que permaneceram presas por mais de quatro meses, embora o prazo para a instrução fosse de sessenta dias. Posteriormente, o entendimento do Supremo Tribunal Federal evoluiu para afirmar que "cabe ao Supremo Tribunal Federal, nos casos excepcionais em que a demora do julgamento do habeas corpus importa em coação ilegal expressiva, conhecer antes que outra autoridade dela possa tomar conhecimento", conforme decisão proferida no Habeas Corpus 41.879 (Ibidem, p. 941).
} 
presidencial, com base no frágil fundamento de que os atos institucionais estariam revigorados e sobrepostos ao texto constitucional superveniente ${ }^{25}$.

O Supremo Tribunal Federal também tinha conhecimento de casos de tortura durante as prisões e as tomadas de depoimentos dos perseguidos políticos. Nesses julgados, foram desconsiderados os relatos de torturas apresentados pelos presos políticos, conforme trecho da Comissão Nacional da Verdade no capítulo que analisa os julgamentos dos Recursos Ordinários Criminais na Corte Suprema:

\begin{abstract}
Muitos dos processos contra os perseguidos políticos que tramitaram na Justiça Militar com acusações de crimes contra a segurança nacional continham denúncias de tortura apresentadas pelos réus, como constatou a pesquisa Brasil: nunca mais. Alguns votos de ministros do STF em recursos criminais mostram que eles tiveram acesso a essas denúncias, sem que tomassem providências a seu respeito e, no mais das vezes, sem que condenassem expressamente o uso da violência contra os presos políticos. Por exemplo, no RC 1.113, julgado em 3 de setembro de 1971, o voto do ministro relator Raphael de Barros Monteiro indicou que as evidências de tortura não seriam razão suficiente para a desconsideração da confissão, se outros elementos a corroborassem [...]

Dessa forma, não há dúvida de que as notícias das graves violações de direito humanos praticados pela ditadura militar contra perseguidos políticos chegaram ao conhecimento do STF. Em alguns dos acórdãos acima mencionados, a prática de tortura por agentes do Estado foi expressamente admitida por ministros no contexto dos debates a respeito das provas admissíveis para a condenação de pessoas pela prática de crimes contra a segurança nacional, sem que se determinasse que fossem investigadas as denúncias de tortura (BRASIL, 2014, p. 947).
\end{abstract}

As demais instâncias também foram responsáveis por emitir julgamentos que legitimaram práticas desumanas do Estado e que se olvidaram da aplicação de garantias mínimas às vítimas desses excessos. O caso da Guerrilha do Araguaia ilustra bem esse tipo de postura do Poder Judiciário. Na última década da ditadura, em 1982, os familiares de mortos e desaparecidos da guerrilha ajuizaram a primeira ação com a finalidade de condenar a União a indicar os locais das sepulturas dos seus parentes ${ }^{26}$. Em 1985, a sentença de primeiro grau extinguiu esse processo sem julgamento de mérito por impossibilidade jurídica do pedido.

\footnotetext{
${ }^{25}$ O julgamento refere-se ao Mandado de Segurança n ${ }^{\circ}$ 18.973, no qual o Supremo Tribunal Federal decidiu que: “o advento da Constituição e a adoção de um sistema novo não justificaria a interrupção da aplicação de um processo apoiado em um texto legal que tem seu fundamento no ato institucional, aprovados esses atos pela Constituição que os revigorou" (Ibidem, p. 938).

${ }^{26}$ Processo 82.00.24682-5, que tramitou perante a $1^{\text {a }}$ Vara Federal da Seção Judiciária do Distrito Federal.
} 
Segundo o fundamento da sentença, não existia qualquer norma que obrigasse a União a indicar o local onde estariam os corpos dos falecidos ${ }^{27}$.

O Poder Judiciário tinha ciência de várias atrocidades cometidas pelo Poder Executivo e sucumbiu à repressão autoritária, seja por meio da chancela judicial dos atos do governo militar, seja por meio de silenciosa omissão. Ao agir dessa forma, o Judiciário foi essencial para transmitir certa aparência de justiça aos abusos que insistiam em prevalecer na ditadura militar. Com controle parlamentar e confirmação judicial, o autoritarismo centralizado no governo foi capaz de prosperar por mais de duas décadas, com prejuízo para a democracia e para os cidadãos. O Relatório da Comissão da Verdade expressa essa mesma conclusão:

Destarte, sublinha-se que, em conjunto, as decisões do Poder Judiciário, quando do
período ditatorial, refletem, muitas vezes, seu tempo e seus senhores; são expressões
da ditadura e de seu contexto de repressão e violência. Os magistrados que ali
estiveram - ou melhor, que ali permaneceram - frequentemente eram parte dessa
conjuntura, inclusive porque, por meio da ditadura militar, foi-lhes garantido um
assento naqueles tribunais. Quem quer que tenha sido nomeado para o STF, por
exemplo, durante a ditadura, tinha clareza das circunstâncias a que estavam jungidos
e quais votos eram esperados da sua lavra; sabiam da ausência de garantias dos
magistrados; conheciam as reformas promovidas na composição e atribuições do
tribunal; e, sobretudo, eram cônscios acerca de quem deveriam servir. Nesse
contexto, conclui-se que a omissão e a legitimação institucionais do Poder Judiciário
em relação às graves violações de direitos humanos, então denunciadas, faziam parte
de um sistema hermético mais amplo, cautelosamente urdido para criar obstáculos a
toda e qualquer resistência ao regime ditatorial, que tinha como ponto de partida a
burocracia autoritária do Poder Executivo, passava por um Legislativo leniente e
findava em um Judiciário majoritariamente comprometido em interpretar e aplicar o
ordenamento em inequívoca consonância com os ditames da ditadura (BRASIL,
2014, p. 957).

Em certo grau, a sociedade civil foi responsável pelos abusos do governo ditatorial, seja por meio da participação direta, seja por meio de omissões que permitiram tais as repressões. Com o Poder Judiciário não foi diferente, o que reforça a natureza civil-militar da ditadura $^{28}$. Decisões judiciais legitimaram atos praticados pela ditadura, aproximaram-se dos

\footnotetext{
${ }^{27}$ Apenas no ano de 1993, portanto após a Constituição Federal de 1988, essa sentença foi reformada pelo Tribunal Regional Federal da $1^{a}$ Região. O acórdão de segunda instância foi mantido nos tribunais superiores. Ainda assim, apenas no ano de 2006 foram especificadas as providências que deveriam ser adotadas pela União em primeira instância. Novos recursos foram interpostos. A fase de cumprimento de sentença teve início no ano de 2009.

${ }^{28}$ Parte da doutrina tem destacado o apoio de setores da sociedade civil durante todo o período da ditadura militar. Esse amparo ocorreu em empresas (siderúrgicas, petroleiras, bancárias e automobilísticas), organizações sociais (instituições religiosas, representativas de classe) e nos órgãos públicos, inclusive no Poder Judiciário. Sobre a participação civil na ditadura militar, conferir o documentário Cidadão Boilesen, 2009, direção Chaim Litewski.
} 
interesses governamentais e abandonaram a aplicação de direitos àqueles contrários ao regime.

Em razão da inevitável parcela de participação do Poder Judiciário no passado ditatorial, esse poder deve se integrar às alterações institucionais que buscam a melhor transição do regime totalitário para o Estado Democrático de Direito. Além da responsabilidade institucional, o Poder Judiciário deve ter consciência de que, ao exercer as funções jurisdicionais, em um contexto de redemocratização e fortalecimento de direitos humanos, terminará por exercer relevante papel no processo transicional brasileiro.

\section{O Poder Judiciário e as Dimensões da Justiça de Transição}

A Justiça de Transição compreende o conjunto de mecanismos capazes de enfrentar o passado autoritário e construir um caminho de democracia e respeito aos direitos humanos, com diversas vertentes: judiciais ou extrajudiciais; nacionais ou transnacionais; preventivos ou repressivos; individuais ou coletivos; sociais ou institucionais. A partir dessa variedade e amplitude de atuação, a doutrina tem classificado as medidas de justiça de transição em quatro principais pilares: a) reparação às vítimas; b) processamento dos perpetradores de violações a direitos humanos; c) políticas de memória; e d) reforma das instituições (ALMEIDA, 2010, p. 42). Essas quatro dimensões são harmônicas entre si e possuem equitativa importância para a justiça transicional.

Conforme menciona Paulo Abrão, o sistema de justiça transicional brasileiro concentra-se especialmente nas competências do Poder Executivo (ABRÃO, 2015, p. 377). De fato, grande parte das atividades de justiça de transição no Brasil são mais facilmente perceptíveis na atuação desse poder. Por exemplo, a reparação às vítimas em geral centralizase na atuação conjunta da Comissão de Anistia com o Ministério da Justiça ${ }^{29}$. No campo da memória, as Caravanas de Anistia $^{30}$ e o Arquivo Nacional ${ }^{31}$ estão igualmente sob a responsabilidade do Ministério da Justiça.

\footnotetext{
${ }^{29}$ Lei $10.559 / 2002$. Artigos 10 e 12.

${ }^{30}$ Sobre as Caravanas da Anistia, ver: Brasil. Caravanas da anistia: o Brasil pede perdão. COELHO, Maria José H.; ROTTA, Vera (Org.). Brasília, 2012.

${ }^{31}$ Portaria $\mathrm{n}^{\mathrm{o}}$ 2.433/2011 do Ministério da Justiça.
} 
Eneá de Stutz e Almeida e Marcelo D. Torelly vão além e observam que as duas dimensões da reparação às vítimas e do processamento dos perpetradores de violência possuem características que se identificam com a atuação judicante, ideia que se remete ao Poder Judiciário; embora, na verdade, essa atividade possa ocorrer em julgamentos judiciais ou em julgamentos administrativos, tal como ocorre no Brasil com a Comissão de Anistia. Já as outras duas dimensões da reforma das instituições e da construção de memória possuem um perfil mais político e gerencial, que se traduzem em identidade com os Poderes Executivo e Legislativo. Com isso, seguem os autores, é possível identificar o terreno fértil para cada grupo de atividades transicionais:

\begin{abstract}
Cada um destes conjuntos apresenta características próprias, porém, grosso modo, pode-se dizer que os dois primeiros conjuntos [reformas institucionais e políticas de memória] agregam um perfil mais político (traduzindo-se em medidas que dependem da aprovação da maioria, diretamente ou representada), enquanto os dois últimos [reparação às vítimas e processamento dos perpetradores] um perfil mais legal (uma vez que pode-se, formalmente, depreender sua necessidade desde o próprio ordenamento jurídico). Com essa constatação é possível identificar os fóruns privilegiados para a implementação de cada conjunto de medidas. Enquanto as reformas institucionais e administrativas, bem como as políticas para a reconciliação, memória e esquecimento são prioritariamente conduzidas pelos poderes Legislativo e Executivo, as políticas de reparação as vítimas tendem a ser implementadas por tribunais (mesmo quando tribunais administrativos com competência extraordinária, situados no Executivo, num modelo que a classificação de Elster definiria como de justiça administrativa legal) e a responsabilização por crimes e atrocidades, prioritariamente, processadas pelo sistema regular de justiça nacional (sendo o uso do sistema internacional um indício de ineficiência do nacional). Desta feita, não faz sentido imaginar um tribunal conduzido pelo Poder Legislativo, ou, ainda, que o Judiciário seja o agente a deliberar sobre quais reformas deve o Estado empreender para que as violações aos direitos humanos não tornem a acontecer (ALMEIDA, 2010, p. 42).
\end{abstract}

À mesma conclusão é possível chegar a partir das reflexões temporais trazidas por Fraçois Ost. $\mathrm{O}$ autor esclarecer que, em um primeiro momento, o juiz sentencia com um olhar para o passado, enquanto o legislador projeta uma promessa para o futuro. Com o mesmo cuidado, o autor lembra que a norma proposta pelo legislador também reescreve o passado e a decisão do juiz é igualmente capaz de influenciar os eventos futuros:

Por aí se vê que a retroactividade do julgamento, longe de ser uma anomalia como no caso da lei, é pelo contrário da própria essência da decisão. O legislador prepara o futuro, cabe-lhe reescrever o passado; o juiz, pelo contrário, diz o direito para o passado (desligando assim aquilo que havia sido desajeitada ou injustamente ligado), e é com problemas que se pronuncia por via de regra geral válida para o futuro (OST, 1999, p. 191).

Assim, os dois pilares de reposição às vítimas e de justiça contra os perpetradores pareceriam se relacionar mais aos fatos pretéritos, ao passo que os pilares da memória e das 
reformas institucionais se voltariam mais para as promessas de um futuro de não repetição. Mas, a partir das mesmas ressalvas feitas acima, pode-se inferir que as indenizações às vítimas e as prisões de torturadores sejam igualmente capazes de imprimir um novo sentido ao futuro de uma sociedade, enquanto as políticas de lembrança e as reformas das instituições apresentam-se como soluções viáveis para uma releitura do passado coletivo.

Com esse pensamento, não é difícil compreender que os três poderes, Legislativo, Executivo e Judiciário, podem atuar nas quatro dimensões da justiça de transição. Uma das características da justiça de transição é justamente permitir uma abertura conceitual e repensar institutos jurídicos tradicionais. Basta lembrar da possibilidade da reparação de danos ou do processamento de violares de direitos humanos, mesmo após o transcurso de prazos prescricionais ou decadenciais, por exemplo. Essa amplitude típica da justiça transicional está exposta em conferência realizada pela Organização das Nações Unidas:

\begin{abstract}
Apesar de seu caráter recente, essa 'justiça especial' tem como fundamento quatro 'pilares' essenciais que, em contrapartida, fornecem diversos mecanismos com os quais uma sociedade marcada pelo ódio e devastadora violência possa começar um processo de conciliação e normalização. De forma mais concreta, o objetivo da justiça de transição é lidar com o pesado legado de abusos de uma maneira mais abrangente e completa, que compreende o direito à verdade, o direito à justiça, o direito à reparação e as garantias de não repetição com o advento de reformas institucionais. Entretanto, a área da justiça transicional é suficientemente abrangente e aberta para permitir abordagens novas e inovadoras a fim de atingir um ou mais de seus objetivos (MOTTET; POUT, 2011, p. 12) ${ }^{32}$.
\end{abstract}

O direito transicional, nessa linha de pensamento jurídico flexível, identifica-se com os movimentos de reformulações de teorias jurídicas, de forma sensível ao campo social, tal como o Direito Achado na Rua (SILVA, 2015, p. 473). Nem poderia ser diferente, pois a mudança de um regime opressor para uma tentativa reconciliação traduz-se em um passo tão importante na busca da democracia que simplesmente se mostra incompatível com a simplicidade de um pensamento acadêmico ortodoxo, antigas previsões legislativas ou decisões judiciais intransigentes. Trata-se, como dito por Reyes Mate, de uma trajetória de

\footnotetext{
${ }^{32}$ Tradução livre deste original em francês: "En dépit de son caractère récent, cette 'justice spéciale' repose sur quatre 'piliers' essentiels qui, à leur tour, fournissent de nombreux mécanismes sur lesquels une société meurtrie par la haine et la violence dévastatrices pourra amorcer un processus d'apaisement et de normalisation. Plus concrètement, l'objectif de la justice transitionnelle est de faire face au lourd héritage des abus d'une manière large et holistique qui englobe le droit à la vérité, le droit à la justice, le droit à la réparation, et les garanties de non-répétition par l'avènement de réformes institutionnelles. Cependant, le domaine de la justice transitionnelle est suffisamment large et ouvert pour permettre de prendre en compte de nouvelles approches innovatrices et susceptibles de répondre à l'un ou plusieurs de ses objectifs".
} 
natureza excepcional, a ensejar a inovação das concepções jurídicas que precisam ser repensadas:

\begin{abstract}
Esta normalização da justiça transicional não elucida todas as dúvidas do jurista na etapa anterior. Porque se já não há diferença entre o funcionamento do Estado de Direito em uma sociedade democraticamente consolidada e outra em transição, o que se desprende é uma perda de rigor na aplicação do Estado de Direito em uma sociedade democrática consolidada. Ao final, a justiça transicional está ligada a circunstâncias políticas excepcionais, daí a flexibilidade na sua aplicação; sem se esquecer, por outro lado, todas essas aderências meta- jurídicas com que se conduziram ou reconduziram a justiça transicional na etapa anterior (Teitel, 2011, 169) (MATE, 2015, p. 157) ${ }^{33}$.
\end{abstract}

Esse pensamento permite defender que o Poder Judiciário será igualmente um dos atores responsáveis por participar do processo transicional brasileiro. Com um passado tão influenciado quanto influenciador da ditadura militar, o Judiciário surge no cenário de redemocratização com as tarefas de garantir a proteção aos direitos humanos, permitir o desenvolvimento da ordem democrática social e buscar a redução de desigualdades. $\mathrm{O}$ princípio constitucional da inafastabilidade, tão tolhido na ditadura, retorna na constituinte de 1988 com qualidade de cláusula pétrea, sem aparentes limites no texto constitucional $^{34}$ e termina por acarretar um quadro de constante judicialização do direito brasileiro ${ }^{35}$.

Nesse contexto, o Poder Judiciário, no exercício da atividade jurisdicional, aplicará o direito dentro de cada um dos quatro pilares da justiça de transição ${ }^{36}$. Por isso, sem prejuízo das atividades dos demais poderes, as decisões proferidas pelo Judiciário têm a capacidade de interferir diretamente no curso do processo de justiça transicional brasileiro. Para reforçar esse

\footnotetext{
33 Tradução livre do seguinte texto escrito em espanhol: "Esta normalización de la justicia transicional no despeja todas las dudas del jurista en la etapa anterior. Porque si ya no hay diferencia entre el funcionamiento del Estado de Derecho en una sociedad democraticamente consolidada y otra en transición, lo que se desprende es una pérdida de rigor en la aplicación del Estado de Derecho en una sociedad democrática consolidada. Al fin y al cabo, la justicia transicional va ligada a circunstancias políticas excepcionales, de ahí la flexibilidad en su aplicación; sin olvidar, por otro lado, todas esas adherencias meta-jurídicas con las que se ha cargado o recargado la justicia transicional en la etapa anterior (Teitel, 2011, 169)"”.

${ }^{34}$ Artigo $5^{\circ}$, inciso XXXV, da Constituição Federal de 1988. Diz-se sem aparentes limites porque ainda existem situações em que há limites ao Judiciário. Por exemplo, em casos de transgressão praticada por militar, o Poder Judiciário comum apenas realiza o controle formal da prisão.

35 O Conselho Nacional da Justiça efetuou o levantamento "Justiça em Números", que registrou aproximadamente 102 milhões de processos em tramitação no país até o ano de 2016 (BRASIL, 2016, p. 17).

${ }^{36}$ Existe um importante trabalho realizado quanto à análise da justiça de transição no Poder Judiciário: OSMO, Carla (Org.). Judicialização da justiça de transição na América Latina. Brasília: Ministério da Justiça, Comissão de Anistia, Rede Latino-Americana de Justiça de Transição (RLAJT), 2016. Essa publicação, que merece leitura, adota classificações e análises temáticas diferentes da abordagem deste trabalho, que preferiu classificar a atuação do Poder Judiciário nas quatro dimensões conceituais da Justiça de Transição.
} 
raciocínio, são analisados alguns exemplos de atividade judicial que se identificam com cada uma das quatro dimensões do sistema de justiça de transição.

\subsection{Poder Judiciário e Reparação às Vítimas}

Provavelmente, a dimensão da reparação aos prejudicados pelo regime militar representa o campo de atuação mais frequente do Poder Judiciário. Ao analisar, na esfera judicial, a legalidade e a constitucionalidade dos julgamentos administrativos, o Poder Judiciário concorre com a formação do processo de justiça transicional aplicado em espécie.

Um exemplo de atuação do Poder Judiciário no tema da reparação econômica ocorreu no Supremo Tribunal Federal no julgamento do Recurso Extraordinário 553.710, classificado como Tema 394 da Repercussão Geral. Nesse julgado, vítimas de perseguição política pleiteavam o cumprimento integral e único da parte retroativa das indenizações de anistia política pelo Ministro do Planejamento e pelo Ministro da Defesa. O Supremo Tribunal Federal declarou a constitucionalidade do artigo 12, $\S 4^{\circ}$, da Lei 10.559/02, que trata da forma de pagamento dos valores pretéritos devidos aos anistiados políticos, afastou o argumento de ausência de disponibilidade orçamentária e determinou que o Poder Executivo efetuasse imediatamente o cumprimento dessa obrigação ${ }^{37}$. O Relator, Ministro Dias Toffoli, destacou a especial situação jurídica daqueles que sofreram durante o período ditatorial, além da proteção à dignidade e aos direitos fundamentais como base da reparação econômica que deve ser cumprida integralmente ${ }^{38}$.

\footnotetext{
${ }^{37}$ Lei 10.559/02. Artigo 12, § 4": "As requisições e decisões proferidas pelo Ministro de Estado da Justiça nos processos de anistia política serão obrigatoriamente cumpridas no prazo de sessenta dias, por todos os órgãos da Administração Pública e quaisquer outras entidades a que estejam dirigidas, ressalvada a disponibilidade orçamentária".

38 "Nessa linha de julgamento, a recusa de incluir em orçamento o crédito previsto na Portaria no 84/2004 do Ministério da Justiça afronta o princípio da dignidade da pessoa humana, por se tratar de cidadão cujos direitos preteridos por atos de exceção política foram admitidos com anos de atraso pelo Poder Público, não podendo esse se recusar a cumprir a reparação econômica reconhecida como devida e justa por procedimento administrativo instaurado com essa finalidade. A despeito de a própria doutrina reconhecer a dificuldade de delimitação do âmbito de proteção da dignidade e dos direitos fundamentais, não há dúvida de que a opção do legislador, ao normatizar e garantir os direitos a esses anistiados, foi a de propiciar àqueles que tiveram sua dignidade destroçada pelo regime antidemocrático outrora instalado em nosso país um restabelecimento mínimo dessa dignidade. É missão desta Suprema Corte, portanto, como já observado por Ingo Wolfgang Sarlet, transformar a dignidade da pessoa humana 'em realidade vivida e, quem sabe, cada vez menos violada' (Notas sobre a dignidade da pessoa humana na jurisprudência do STF. In: SARMENTO, Daniel \& SARLET, Ingo Wolfgang (Coordenadores). Direitos Fundamentais no Supremo Tribunal Federal: Balanço e Crítica. Rio de Janeiro: Lumen Juris, 2011. p. 73). Havendo o preenchimento desses pressupostos, quais sejam, o
} 
O Poder Judiciário também tem corrigido os valores indenizatórios fixados na esfera administrativa para adequá-los aos termos da Lei 10.559/02. Essa orientação vem sendo adotada nos julgamentos de várias categorias profissionais de anistiados, a fim de permitir a maior fidelidade possível entre o valor da reparação e o montante que é percebido por aqueles que permaneceram em atividade justamente por não terem sofrido prejuízos profissionais durante a ditadura. Noutros julgados, os tribunais entenderam que a reparação dos danos materiais pela anistia política não impede o acréscimo de reparação aos danos morais em determinadas hipóteses.

Há situações em que o Poder Judiciário alterou a forma de reparação econômica. Em um desses casos, o órgão administrativo havia entendido que o anistiado deveria receber prestação única, e não prestação mensal, tendo em vista que atuava como dentista prático na ditadura militar, profissão essa não regulamentada. O Judiciário entendeu que a atividade de dentista prático, embora sem regulamentação, era uma atividade socialmente aceita e bastante comum para aquela época e região do Brasil, o que acarretaria a necessidade de transformação da prestação única em prestação mensal ${ }^{39}$.

Em outro caso, o Poder Judiciário estabeleceu uma indenização adicional para uma vítima que ainda era criança durante a ditadura militar e que passou a vida em busca do pai até encontrá-lo morto em outro país. Nessa oportunidade, o Judiciário considerou insuficiente a reparação administrativa que havia sido estabelecida em prestação única e que se encontrava limitada ao ano em que o pai daquela criança havia sido preso. A sentença esclareceu a necessidade de ampliação indenizatória ${ }^{40}$.

Em todos esses exemplos, os magistrados, analisando questões de fato e de direito, aplicando o comando legislativo pertinente e a Constituição Federal, influenciaram o resultado final da reparação a cada uma das respectivas vítimas. Ao realizar essa função, o

reconhecimento do débito pelo órgão da administração direta em favor do anistiado político militar e a destinação de verba em montante expressivo em lei, não há como se acolher, nos presentes autos, a tese de inviabilidade do pagamento pela ausência de previsão orçamentária para o atendimento da pretensão". BRASIL. Supremo Tribunal Federal. Recurso Extraordinário 553.710 (Tema 394 da Repercussão Geral). Distrito Federal. Relator: Ministro Dias Toffoli. Julgamento do dia 17/11/2016. Acórdão pendente de publicação. Voto disponibilizado pelo Ministro Relator, sujeito a revisão até a publicação do acórdão.

${ }^{39}$ BRASIL. Tribunal Regional Federal da $1^{a}$ Região. Apelação Cível no 0031627-61.2008.4.01.3400. Relator Desembargador Federal Jirair Aram Meguerian. Acórdão Publicado no Diário de Justiça Eletrônico do dia 18/03/2013.

${ }^{40}$ BRASIL. Seção Judiciária do Distrito Federal. Ação Ordinária no ${ }^{\circ}$ 63856-69.2011.4.01.3400. Juízo da $4^{a}$ Vara Federal. Trecho da sentença publicada no Diário de Justiça Eletrônico do dia 04/06/2013. 
Poder Judiciário termina por permitir a realização desse importante pilar da justiça transicional.

\subsection{Poder Judiciário e Processamento dos Violadores de Direitos Humanos}

Existem processos em curso no Poder Judiciário que tratam da alteração do sistema de justiça para possibilitar o processamento dos perpetradores de violação aos direitos humanos. Ganharam repercussão os processos que pretendiam a responsabilização do Coronel Reformado Carlos Alberto Brilhante Ustra pela prática de torturas durante os horrores da ditadura $^{41}$.

Outro exemplo consiste em ação penal ajuizada contra seis acusados de participar da explosão de uma bomba durante a comemoração ao dia do trabalho, evento conhecido como “Atentado ao Riocentro”. Esse caso aguarda apreciação do Superior Tribunal de Justiça ${ }^{42}$.

A reinterpretação das normas jurídicas que autorizam o processamento dos violadores de direitos humanos representa uma das maiores resistências do Poder Judiciário. Várias decisões são proferidas no sentido de impossibilitar esse processamento com base na simples menção ao julgamento da Ação de Descumprimento de Preceito Fundamental (ADPF) $n^{\circ} 153$ pelo Supremo Tribunal Federal. Ocorre que a referida ADPF não decidiu pela impossibilidade de processamento dos perpetradores de violação contra os direitos humanos no período da ditadura, mas simplesmente declarou a constitucionalidade da Lei 6.683/79, a Lei de Anistia. Definiu a compatibilidade dessa Lei em conformidade com a Constituição de 1988, exercendo o mandato constitucional de controle de constitucionalidade.

Informações equivocadas, provavelmente por falta de conhecimento, em especial dos meios de comunicação social, disseminaram o entendimento de que o STF declarou a anistia ampla, geral e irrestrita da Lei 6.683/79 e com isso impediu o processamento judicial de qualquer responsabilização dos eventuais agentes públicos que ainda estejam vivos, seja tal responsabilização na esfera cível, penal ou administrativa. Nada mais equivocado que tal

\footnotetext{
${ }^{41}$ A maior parte dos processos, entretanto, não tiveram acolhimento do Poder Judiciário. Por exemplo, sentença proferida pela $1^{\text {a }}$ Vara Criminal Federal de São Paulo no processo 0016351-22.2014.4.03.6181, que rejeitou a denúncia oferecida contra o torturador com base em alegação de prescrição e anistia aos torturadores.

${ }^{42}$ Superior Tribunal de Justiça. 6 ${ }^{\mathrm{a}}$ Turma. Agravo em Recurso Especial 818.592. Relator Ministro Rogério Schietti. Processo de origem: 0005684-20.2014.4.02.0000.
} 
entendimento, mas pelo menos até 2017 tem sido a postura do Judiciário brasileiro nesta dimensão da Justiça Transicional.

\title{
3.3. Poder Judiciário e a Memória
}

De forma pontual, o Poder Judiciário também tem atuado para corrigir algumas informações equivocadas e inverdades históricas do período de exceção. Nesse sentido, ganhou destaque a sentença do Poder Judiciário, na competência da vara de registros públicos, que determinou a alteração da certidão de óbito do jornalista Vladimir Herzog, assassinado por motivos políticos na ditadura militar. Vale transcrever os seguintes trechos do ato decisório:

\begin{abstract}
A objeção parcialmente oposta pela ilustrada Promotoria de Justiça, no que se refere à anotação da causa da morte, a despeito da firma argumentação invocada, não procede. Seria verdadeiramente iníquo prolongar o martírio da viúva e dos familiares e afrontar a consciência pública nacional, a renovação da investigação sobre a 'causa mortis', quando, de há muito, ficou apurado, em termos de convicção inabaláveis, especialmente, pela via jurisdicional comum, que o jornalista Vladimir Herzog perdeu a vida em razão de maus tratos e de lesões sofridas, em circunstâncias de todos conhecidas. Apegar-se a filigranas jurídicas, na conjuntura apontada, constituiria o reconhecimento inadmissível da continuidade do sofrimento imposto pela imputação de suicídio, cuja versão não foi comprovada segundo definição judicial precedente. A Comissão Nacional da Verdade já assentou o entendimento em relação à matéria, sobre a qual não há mais o que perquirir, nesse particular. [...] A matéria, portanto, reclama o restabelecimento da verdade para adequar, 'ainda que tardia', a ocorrência ao estado de exatidão. Destarte, pelos fundamentos expostos, acolhida a manifestação da digna Comissão Nacional da Verdade, defiro o pleito proposto, para o fim de ordenar a retificação no assento de óbito do jornalista Vladmir Herzog, para contar que a morte decorreu de lesões e maus tratos sofridos em dependência do II Exército - SP (DOI-CODI) ${ }^{43}$.
\end{abstract}

Embora ainda não ocorra dentro da extensão desejada, o Poder Judiciário também proferiu julgados nos quais foi determinada a abertura de documentos importantes para o esclarecimento de fatos e construção de uma memória nacional. Foi o que ocorreu no julgamento da Reclamação Constitucional $n^{\circ} 11.949$, na qual se determinou que o Superior Tribunal Militar disponibilizasse a um grupo de pesquisadores não apenas as gravações das sessões públicas do período da ditadura militar, mas também as gravações das sessões secretas ocorridas na vigência do regime ditatorial ${ }^{44}$. Em seu voto, o Ministro Celso de Mello

\footnotetext{
${ }^{43}$ Sentença proferida no Processo n ${ }^{\circ}$ 0046690-64.2012.8.26.0100 pelo Juízo da 2 ${ }^{\text {a }}$ Vara de Registros Públicos de São Paulo.

${ }^{44}$ BRASIL. Supremo Tribunal Federal. Reclamação 11.949. Distrito Federal. Relatora: Ministra Cármen Lúcia. Julgamento do dia 16/03/2017. Acórdão pendente de publicação. Voto disponibilizado pelo Ministro Celso de Mello, sujeito a revisão até a publicação do acórdão.
} 
registra, com amparo em Norberto Bobbio, que as democracias são incompatíveis com o mistério e que todos os cidadãos têm direito conhecer o passado para fins de exercício da fiscalização social do poder público (BOBBIO, 1986).

Portanto, a dimensão da recordação tem sido posta para apreciação do Judiciário. Nesse campo, o Judiciário colabora para a construção de uma memória social e para a busca da verdade, entendida no conceito de Hannah Arent como tudo aquilo que não se pode modificar, tal como o solo que está abaixo dos nossos pés e o céu que está acima de nossas cabeças (ARENT, 2006, Apud BARBOSA; VANNUCHI, 2009, p. 59).

\subsection{Poder Judiciário e a Reforma das Instituições}

Algumas reformas institucionais e adoções de políticas públicas no período pós redemocratização foram direcionadas para setores do Poder Judiciário. A título exemplificativo, citam-se a previsão constitucional dos juizados de pequenas causas e seus desdobramentos $^{45}$, a criação do Conselho Nacional de Justiça com a finalidade de exercer controle do Judiciário e a possibilidade de descentralização judiciária por meio da justiça itinerante $^{46}$.

Mas também o Poder Judiciário pode ser chamado a tomar decisões que impliquem em outras reformas institucionais. Por exemplo, no ano de 2014, o Conselho Nacional de Justiça instituiu um grupo de trabalho para estudar a reestruturação da Justiça Militar. A análise do Conselho Nacional de Justiça avaliou diversas questões institucionais, desde a possibilidade de extinção das Justiças Militares Estaduais ou da absorção das atribuições da Justiça Militar em varas especializadas da Justiça Comum, até a redução do número de Ministros do Superior Tribunal Militar ${ }^{47}$.

Assim, também o pilar das reformas das instituições pode ser exercido pelo Poder Judiciário. Porém, tão relevante quanto a mudança institucional é a reforma do próprio pensamento do Judiciário para perceber que exerce um relevante papel no sistema de justiça de transição. É importante analisar de forma crítica quais são os elementos presentes nas instituições do Poder Judiciário que revelam resquícios de influência do período de exceção.

\footnotetext{
45 Artigo 24, X, da Constituição Federal. Lei 9.099/95, Lei 10.259/2001, Lei 12.153/09.

${ }^{46}$ Emenda Constitucional 45/2004.

${ }^{47}$ Relatório do Conselho Nacional de Justiça. Grupo de Trabalho instituído pela Portaria 216/2013.
} 
Nessa reflexão, o Poder Judiciário desempenhará não apenas a função judicante, mas também colaborará com os mecanismos que garantam a completude do processo transicional brasileiro.

\section{4. À guisa de conclusão: a necessidade de reforma institucional do Judiciário}

O Poder Judiciário guarda características residuais do regime ditatorial, a exemplo do tradicionalismo, formalismo, exacerbado positivismo e distanciamento da sociedade (LUNARDI, 2012, p. 168). É necessário que o Poder Judiciário se envolva com os demais atores institucionais para se livrar das amarras que o conservadorismo implica ao desenvolvimento da transição da ditadura para o Estado Democrático de Direito. A atividade judicial não deve ser vista como um campo de vingança, mas sim como terreno de atuação social (FABRIZ, 2006, p. 38). Essa legitimação democrática jamais será alcançada se as instituições permanecerem resistentes à compreensão do próprio processo transicional (SOUZA JÚNIOR, 2008, p. 14).

Se a sobrevivência das democracias depende em parte da vitalidade de seus sistemas institucionais, o Poder Judiciário deve realizar uma autoanálise crítica e identificar os predicados que o impedem de dar sequência ao processo transicional brasileiro (PRZEWORSKI, 1997, p. 125). Conforme leciona Paulo Abrão, a necessidade de construções e reconstruções institucionais também recaem sobre o Poder Judiciário:

\footnotetext{
Perante essa gama de abusos, o Estado deve assumir a responsabilidade de promover respostas em diferentes âmbitos: a reparação, a prevenção, a responsabilização criminal, a não repetição. Essas adjetivações qualificam a Justiça de Transição que se pretende em processos de superação efetiva do regime autoritário. Qualificam e norteiam as postulações por reformas institucionais, inclusive na esfera da justiça (ABRÃO, 2015, p. 384).
}

Vanessa Dorneles Schinke lembra que o Poder Judiciário não pode se esquivar de enfrentar todas as consequências que o delicado processo transicional demanda, inclusive com as responsabilidades institucionais dentro do seu próprio poder. Se permanecer avesso a tais mudanças, com posturas contrárias às medidas de verdade ou de reparação por exemplo, o Judiciário exercerá uma força antidemocrática prejudicial às medidas transicionais alcançadas:

Nesse mesmo sentido, ilustra-se a complexidade da questão pela tese construída por Paloma Aguilar (2013, p. 2), no sentido de que, quanto mais direto o envolvimento do Poder Judiciário na repressão autoritária, menos provável é o estabelecimento de 
responsabilização judicial ou de medidas de verdade durante o período de democratização. Ou seja, quando a responsabilidade pela repressão pode recair sobre membros do Poder Judiciário (não se restringindo apenas às forças militares e policiais), juízes e promotores tendem a relutar na aprovação de medidas punitivas contra os repressores. Igualmente, os membros do Poder Judiciário também reagiriam de forma mais incisiva contra a publicização do passado por meio de comissões da verdade, pois o escrutínio público no tocante aos atos judiciais pode denunciar procedimentos realizados sem garantias judiciais mínimas, questionando a lisura e a independência dos órgãos judiciais (SCHINKE, 2015, p. 449 Apud AGUILAR, 2013, p. 2).

Para que a transição seja completa e eficaz, é necessário que o Poder Judiciário seja uma instituição independente, socialmente legitimada e comprometida com os objetivos da justiça transicional. Essas características importarão em um reforço das instituições democráticas com o consequente desenvolvimento de um processo transicional em sua melhor forma e a consolidação de um estado de direito, nos termos expostos por Arnould e Sriram:

\begin{abstract}
Assim como a democracia é um processo multidimensional - envolvendo diferentes níveis de atores (o estado, sociedade, o indivíduo) e diferentes esferas de ação (política, econômica, judicial, social, cultural) — é provável que a justiça de transição tenha impactos diferentes nestas múltiplas dimensões. [...] A Justiça de Transição talvez influencie alguma, mas não todas as dimensões democráticas. [...] No entanto, o grau em que se pode esperar que a justiça transicional tenha um impacto razoável é no desenvolvimento democrático de instituições. Isso indica o fortalecimento dos princípios e das instituições democráticas fundamentais — tal como um judiciário independente, forças armadas democráticas e participação social - bem como a melhoria de desempenho dessas instituições. Embora o desenvolvimento institucional não seja uma condição suficiente para a democracia - que também requer mudanças nas atitudes e convicções bem como remodelagem das relações estado-sociedade e práticas socioeconômicas — é um componente indispensável. [...] O estado de direito é um pilar essencial em que a democracia se apoia enquanto protege direitos, impõe responsabilidades jurídicas e restringe o abuso de poder político. Isso implica na primazia da lei e na sua aplicação igualitária para agentes públicos e privados. Portanto, o componente central do estado de direito reside no desempenho do sistema judicial: o judiciário precisa ser independente, acessível, efetivo e respeitar os princípios do devido processo, legalidade e igualdade. A justiça transicional busca alguns dos mesmos objetivos do estado de direito - promover justiça e proteção aos direitos humanos - e, consequentemente, muitas vezes age em complemento à política do estado de direito. Mas também se espera que a justiça de transição contribua diretamente para a construção do estado de direito em países que estão em transição de regras autoritárias ou conflitos armados, reafirmando o princípio da identificação de responsabilidades, encorajando mudanças nas práticas judiciais ou focando em debates políticos e societários em questões de justiça. A justiça transicional aprofunda debates, sustenta o estado de direito por meio da educação das pessoas sobre padrões mínimos de direitos e induz governos a agir em conformidade com conhecidos direitos humanos e com regras de um estado de direito (ARNOULD; SRIRAM, 2014, p. 3) ${ }^{48}$.
\end{abstract}

\footnotetext{
48 Tradução livre do seguinte texto original escrito em língua inglesa: "As democracy is a multidimensional process - involving different levels of agency (the state, society, the individual) and different spheres of action
} 
Principalmente, o Poder Judiciário deve ter a percepção de que faz parte de um processo transicional no curso da história brasileira. Justamente essa consciência ainda não foi alcançada por esse poder. Duas principais razões fundamentam essa assertiva.

Em primeiro lugar, infelizmente, ainda se mostra elevado o número de decisões judiciais que mostram desconhecimento da matéria ou que se recusam a aplicar as normas próprias do sistema de justiça transicional brasileiro ${ }^{49}$. Um outro exemplo dessa falha está estampado na condenação do Estado Brasileiro pela Corte Interamericana de Direitos Humanos no caso da Guerrilha do Araguaia (Gomes Lund), pois a necessidade do uso de um sistema internacional de justiça revela um indício de ineficiência do sistema de justiça nacional (ALMEIDA, 2010, p. 43 e ABRÃO, 2015, p. 384-385).

Em segundo, uma simples pesquisa pelo termo "justiça de transição" nos bancos de dados jurisprudenciais dos tribunais brasileiros mostra que praticamente não há julgamentos com essa expressão ${ }^{50}$. Contudo, como visto no tópico anterior, esses mesmos tribunais estão se debruçando sobre questões de tortura, violações a direitos humanos no regime militar,

(political, economic, judicial, social, cultural) - transitional justice is likely to have a differing impact on these multiple dimensions. [...] Transitional justice may impact some but not all democracy dimensions. [...] However a level at which transitional justice can reasonably be expected to have na impact is democratic institutionbuilding. This refers to the strengthening of foundational democratic institutions and principles - such as an independent judiciary, democratic security forces, and participation - as well as the improvement of the performance of these institutions. While institution-building is not a sufficient condition for democracy - which also requires changes in attitudes and beliefs as well as a remoulding of state-society relations and socioeconomic practices - it is a necessary component of it. [...] Rule of law is an essential pillar on which democracy rests as it protects rights, enforces accountability and constrains political abuse of power. It entails the primacy of the law and its equal application to all public and private agents. A central component therefore of rule of law is the performance of the judicial system: the judiciary needs to be independent, accessible, effective, and respect the principles of due process, legality and equality. Transitional justice pursues some of the same objectives as rule of law - promoting justice and human rights - and is therefore often seen as acting in complement to rule of law policies. But transitional justice is also expected to directly contribute to building the rule of law in countries transitioning from authoritarian rule or armed conflict by reasserting the principle of accountability, encouraging changes in judicial practice, or focusing societal and political debates on questions of justice. Transitional justice, it is further argued, supports rule of law by educating people about rights standards and inducing governments to act in line with publicly known human rights and rule of law standards".

${ }^{49}$ Por exemplo, na Ação Ordinária no 2009.34.00.032086-3, foi proferida sentença pela 22a Vara Federal da Seção Judiciária do Distrito Federal por meio da qual julgou prescrita a ação de reparação de danos morais e materiais de um anistiado que foi preso na Operação Bandeirantes, comandada pelo Delegado Sérgio Paranhos Fleury, notório torturador no regime militar. Outro exemplo, na Ação Ordinária no 2009.34.00.016425-6, a sentença da $7^{\text {a }}$ Vara Federal da Seção Judiciária do Distrito Federal entendeu que a União não possuía legitimidade passiva para responder por processos de anistia e que o anistiado deveria se voltar contra a empresa que o demitiu, no caso a siderúrgica Açominas.

${ }^{50}$ No Supremo Tribunal Federal, o único acórdão identificado na busca jurisprudencial com a pesquisa do termo "justiça de transição" é o julgamento da ADPF 153. No Superior Tribunal de Justiça, a pesquisa de jurisprudência não identificou nenhum acórdão com esse termo, apenas uma única decisão monocrática proferida no Agravo em Recurso Especial nº 1.066.047. 
reparações de danos ocorridos durante a ditadura, além de outros assuntos e institutos próprios da justiça transicional ${ }^{51}$. É como se o Poder Judiciário conhecesse apenas a espécie, mas sem ao menos conhecer o gênero dos institutos jurídicos analisados. Ao tratar de danos e reparações decorrentes do regime militar, temas relacionados à memória, reformas institucionais ou processamento de perpetradores de violência, o Judiciário deve saber que tais assuntos representam a realização de uma justiça de transição no cenário nacional. Vanessa Schinke mostra os desafios a serem enfrentados pelo Judiciário nessa seara:

Atualmente, a Justiça de Transição desafia o Poder Judiciário brasileiro a ultrapassar o exercício burocrático de suas atribuições em prol da irradiação dos princípios constitucionais de proteção do ser humano e, consequentemente, de fortalecimento do Estado Constitucional. Quanto à resolução de conflitos, embora sabidamente o Poder Judiciário não seja o único espaço em que isso seja possível - a exemplo da orgânica gestão de conflitos produzida pela sociedade civil (mais ou menos organizada), em que as situações são melhor gestadas e resolvidas longe dos tribunais -, deve-se reconhecer que o espaço do Poder Judiciário é relevante para irradiar e para consolidar sentidos e registros simbólicos sobre o direito. Além de constituir-se em um meio de acesso à Justiça, ao filiar-se a uma interpretação que assegure a proteção aos direitos humanos - diante de casos que envolvam graves violações de direitos humanos -, o Poder Judiciário pode-se caracterizar como um lugar de combate à impunidade, de busca pela verdade, de reparação e de construção de memória [...] A Justiça de Transição, por excelência, confronta os limites de atuação discursivo-burocrática do Poder Judiciário na medida em que o incita a deslocar sua preocupação com a aplicação de argumentos pragmáticos e tecnicistas para concretizar princípios de proteção dos direitos humanos. [...] O caso brasileiro sobre a judicialização da Justiça de Transição evidencia a necessidade de o Poder Judiciário adotar uma interpretação produtiva sobre normas de proteção aos direitos humanos (SCHINKE, 2015, p. 450).

Ao tomar consciência de que o exercício da função jurisdicional impacta não apenas nos casos específicos e concretos julgados, mas em todo o sistema de justiça transicional, o Poder Judiciário saberá que as decisões judiciais nesses casos serão capazes de reduzir conflitos, auxiliar na formação de uma democracia duradoura, com instituições fortalecidas e amparo social. Ao enfrentar destemidamente o passado e aplicar as normas de justiça transicional, o Poder Judiciário evita a repetição de erros que de forma recorrente tendem a ressurgir.

Um Poder Judiciário com um pensamento crítico e consciente, sabedor de seu papel e comprometido com o processo transição brasileiro, essa é uma das bases para a construção de instituições sólidas e para a busca de uma democracia socialmente legitimada. Afinal,

\footnotetext{
${ }^{51}$ Em ambos os tribunais, aparecem centenas de julgados quando a pesquisa é feita pelas palavras "ditadura", "tortura e militar", "anistia política" etc.
} 
conforme lembra James Cavallaro, "hoje, na América Latina, os países que mais respeitam os direitos humanos são precisamente aqueles que passaram por períodos terríveis de repressão e que gradualmente aprenderam a lidar com o passado de abusos" (Apud, BARBOSA; VANNUCHI, 2009, p. 55).

\section{Bibliografia}

ABRÃO, Paulo; RAMPIN, Talita Tatiana Dias; FONSECA, Lívia Gimenes Dias da. Direito à Justiça e Reforma das Instituições. In: SOUSA JUNIOR, José Geraldo de; SILVA FILHO, José Carlos Moreira da; PAIXÃO, Cristiano; FONSECA, Lívia Gimenes Dias da; RAMPIN, Talita Tatiana Dias. $O$ direito achado na rua: introdução crítica à justiça de transição na América Latina. Brasília: UnB, O direito achado na rua, v. 7, 2015.

ALMEIDA, Eneá de Stutz e; e TORELLY, Marcelo D. Justiça de Transição, Estado de Direito e Democracia Constitucional: Estudo preliminar sobre o papel dos direitos decorrentes da transição política para a efetivação do estado democrático de direito. In Sistema Penal \& Violência: Revista Eletrônica da Faculdade de Direito PUCRS, Porto Alegre, v. 2, n. 2, 2010.

AGUILAR, Paloma. Judiciary Involvement in Authoritarian Repression and Transitional Justice: The Spanish Case in Comparative Perspective. International Journal of Transitional Justice, v. 7, n. 2, 2013, p. 245-266.

ARENT, Hannah. Entre o passado e o futuro. São Paulo: Perspectiva, 2006.

ARNOULD, Valerie; SRIRAM, Chandra Lekha. Pathways of Impact: How Transitional Justice Affects Democratic Institution-Building. In TJDI Policy Paper, $\mathrm{n}^{\mathrm{o}} 1$, 2014.

BARBOSA, Marco Antônio Rodrigues; e VANNUCHI, Paulo. Resgate da memória e da verdade: um direito de todos. In SOARES, Inês Virgínia Prado Soares; KISHI, Sandra Akemi Shimada. Memória e Verdade: A Justiça de Transição no Estado Democrático Brasileiro. Belo Horizonte: Fórum, 2009.

BRASIL. Caravanas da anistia: o Brasil pede perdão. COELHO, Maria José H.; ROTTA, Vera (Org.), Brasília, 2012.

BRASIL. Comissão Nacional da Verdade. Relatório da Comissão Nacional da Verdade. 2014, Capítulo 17.

BRASIL. Conselho Nacional de Justiça. Justiça em números. Brasília, 2016.

FABRIZ, Daury Cesar. Cidadania, democracia e acesso à justiça. In ALMEIDA, Eneá de Stutz e (Org). Direitos e Garantias Fundamentais. Florianópolis: Fundação Boiteux, 2006.

LUNARDI, Fabrício Castagna. A justiça de transição no Brasil: a transição política, a reforma das instituições e o desenvolvimento da democracia. São Paulo: Revista dos Tribunais, ano 101, vol. 924, 2012. 
MATE, Reyes. Memoria y justicia transicional. In ABRÃO, Paulo; RAMPIN, Talita Tatiana Dias; FONSECA, Lívia Gimenes Dias da. Direito à Justiça e Reforma das Instituições. In: SOUSA JUNIOR, José Geraldo de; SILVA FILHO, José Carlos Moreira da; PAIXÃO, Cristiano; FONSECA, Lívia Gimenes Dias da; RAMPIN, Talita Tatiana Dias. $O$ direito achado na rua: introdução crítica à justiça de transição na América Latina. Brasília: UnB, O direito achado na rua, v. 7, 2015.

MOTTET, Carol; POUT, Christian (Ed.). La justice transitionnelle: une voie vers la réconciliation et la construction d'une paix durable. Conference Paper Dealing with the Past Series. Iaundé, Camarões, 2011.

ORGANIZAÇÃO DAS NAÇÕES UNIDAS. The rule of law and transitional justice in conflict and post-conflict societies. Relatório da Secretaria Geral do Conselho de Segurança. Nova Iorque, 2004.

OSMO, Carla (Org.). Judicialização da justiça de transição na América Latina. Brasília: Ministério da Justiça, Comissão de Anistia, Rede Latino-Americana de Justiça de Transição (RLAJT), 2016.

OST, François. O tempo do direito. Lisboa, 1999.

PRZEWORSKI, Adam; ALVAREZ, Michael; CHEIBUB, José Antonio; LIMONGI, Fernando. O que mantém as democracias? Lua Nova: Revista de Cultura e Política, 1997.

SILVA, Fábio de Sá e. Voos de andorinhas: uma cartografia exploratória de sujeitos e práticas instituintes de direito (à memória, à verdade e à justiça) nos marcos de O Direito Achado na Rua. In ABRÃO, Paulo; RAMPIN, Talita Tatiana Dias; FONSECA, Lívia Gimenes Dias da. Direito à Justiça e Reforma das Instituições. In: SOUSA JUNIOR, José Geraldo de; SILVA FILHO, José Carlos Moreira da; PAIXÃO, Cristiano; FONSECA, Lívia Gimenes Dias da; RAMPIN, Talita Tatiana Dias. O direito achado na rua: introdução crítica à justiça de transição na América Latina. Brasília: UnB, O direito achado na rua, v. 7, 2015.

SOUSA JÚNIOR, José Geraldo de. Ideias para a cidadania e para a justiça. Porto Alegre: Sergio Antônio Fabris Editor, 2008, p. 14. 